Article

\title{
"We Have Advised Sex Workers to Simply Choose Other Options"-The Response of Adult Service Websites to COVID-19
}

\author{
Lilith Brouwers $^{1, *(\mathbb{D})}$ and Tess Herrmann ${ }^{2} \mathbb{D}$ \\ 1 Leeds University Business School, University of Leeds, Leeds LS6 1AN, UK \\ 2 Department of Social Policy and Social Work, University of York, York YO10 5DD, UK; \\ Tess.Herrmann@york.ac.uk \\ * Correspondence: L.H.Brouwers@leeds.ac.uk
}

Received: 30 August 2020; Accepted: 29 September 2020; Published: 13 October 2020

\begin{abstract}
In-person sex work is one of the industries most directly affected by the COVID-19 pandemic. In order to connect with clients, most independent sex workers use adult service websites (ASWs), whose services range from simple advertising websites to platforms with both direct and indirect governance of workers. Although ASWs do not employ sex workers, their response to the pandemic has a large impact on sex workers' financial and physical wellbeing. This effect is even stronger among migrant workers, who are less likely to qualify for, or be aware they qualify for, government support. This study reviews the response to COVID-19 of 45 of the leading ASWs in Britain, and triangulates the data with seven sex worker-led organisations. It shows a large variation in the responses of ASWs: the majority had no public response to the pandemic at all, a minority took intentional steps to support workers or donated to hardship funds for sex workers, and at least one ASW reduced their safety features during the pandemic. These findings illustrate that while most ASWs do not acknowledge the influence they have over the working practices of their service users and the shift of economic risk to them, some recognised the potential that their platforms have to support sex workers during crises.
\end{abstract}

Keywords: sex work; adult entertainment; intermediaries; platform work; COVID-19; migrant workers; online sex work; prostitution; adult service websites

\section{Introduction}

In-person sex workers are uniquely affected by the COVID-19 health crisis and lockdown. This is both because their work involves close physical contact for extended periods of time, making it a high-risk profession (NHSGGC Communications 2020), and because it is hard or in some cases impossible for them to access the pandemic-related financial support the government has made available. Sex workers are therefore more likely to need to continue working during lockdown, even if this does not comply with the government guidelines regarding social distancing. Since many sex workers work without a third party and connect to potential clients through the internet, adult service websites (ASWs) which provide a space for workers and clients to connect are an important part of many sex workers' business model.

As ASWs play such an important role in connecting a large proportion of in-person sex workers with their clients, they have the potential to influence the way both clients and workers respond to the COVID-19 pandemic. ASWs have the ability to advise sex workers, clients, or both on risks and alternatives, can add or limit the services they offer, and can directly or indirectly financially support the workers who use their platform. In what follows, we argue that the degree of control these 
intermediaries have has increased during the pandemic, especially with regards to migrant workers who may be less able to access government support (Ehata and Seeleib-Kaiser 2017). We further argue that the majority of ASWs do not recognise the existence of a relationship of dependence between sex workers and themselves, and in some cases even deny it. Sex worker-led organisations, on the other hand, are very aware of the power imbalances in this relationship. The COVID-19 pandemic has also illustrated that most ASWs do not treat sex workers and their clients in the same way, resulting in the responsibility for public health as well as economic risks being transferred from ASWs to sex workers, and completely circumventing clients. This further exacerbates the hardship that many sex workers, particularly those without British citizenship, face during this pandemic. This article contributes to an emerging body of literature (Barbagallo and Hardy forthcoming; Jones 2015) which studies the influence of ASWs on sex workers' working conditions, and which remains under-theorised. This article maps the responses of ASWs to the COVID-19 pandemic in Britain, and investigates which actions sex worker-led organisations would like to see from ASWs. It reveals a large disparity between the responses or lack thereof of many ASWs, and the level of response representatives of British sex workers wished to see. There are some ASWs that have taken direct action to support the health and income of sex workers during the COVID-19 lockdown. Their response reveals their financial abilities as well as high levels of influence on the sex industry, both of which ASWs could use to support sex workers during crises.

In the first part of this article, we outline the existing literature on ASWs, illustrating their business model and situating their ambiguous role as intermediaries in the wider context of atypical employment relationships. In doing so, it becomes clear that the important role that ASWs play in connecting sex workers with their clients creates a relationship of dependence that remains under-theorised. In order to contextualise the response of ASWs to the pandemic, this article then gives attention to the effects of COVID-19 on sex workers. We highlight the fact that many people who sell sex in Britain, especially migrants, were neglected by governmental support schemes and were forced to continue offering sexual services in person, which is often mediated by ASWs. We move on by describing the methods used for the processing of our data before turning to a grouped outline of the responses of ASWs to the pandemic. Our results map both publicly available information and additional information obtained in a survey about the actions taken by various ASWs. We further triangulate those responses with the experiences and expectations sex worker-led organisations have had with ASWs during COVID-19. This data shows that ASWs do not simply treat sex workers as service users, as they do clients of sex workers, but instead exercise control. We contrast this with the fact that ASWs do not acknowledge their role as intermediaries, and conclude that the combination of high levels of control and the shifting of financial and health risk by ASWs has become even more pronounced during the pandemic.

\section{Adult Service Websites}

In the UK, sex work itself is not criminalised but many third-party activities including management and client procurement are (Brown et al. 2019). Many sex workers work independently and promote their services to potential clients either outside or online (Sanders et al. 2016). For independent workers who work indoors, the internet has become crucial for client recruitment (Jones 2015). One influential avenue for reaching clients is the use of adult service websites ${ }^{1}$ (ASWs). ASWs offer a wide range of services, from simple classified ads to large platforms offering a range of services (Sanders et al. 2018) and some of the larger platforms can be better theorised as intermediaries in in-person sex work (Barbagallo and Hardy forthcoming) which control many aspects of sex workers' advertising and screening processes. For the purpose of this paper, we define adult service websites as third-party

1 The term "Adult Service Websites" is used as an umbrella term in various policy papers and reports, such as the National Police Chief's Council (NPCC) guidelines on sex work to refer to 'websites, accessible via the internet to anyone declaring they are at least 18 years old, that advertise sexual services to customers either as a segment of their business or as their sole business' (NPCC 2019, p. 17). 
internet platforms where independent in-person sex workers, as well as agencies and venues in some cases, advertise their services directly to potential clients. This excludes agency homepages, individual workers' websites, and websites that are exclusively webcam and adult content sites, although some ASWs also offer webcamming and phone sex features or facilitate the sale of clips and photographs in addition to advertisement of in-person meetings.

Online advertising has increasingly replaced print media advertising (Jones 2015) as well as street soliciting (Cunningham and Kendall 2010). This has provided sex workers with additional screening methods and means to connect with one another but also resulted in entirely new risks, such as capping or doxing (Jones 2015).

Sanders et al. (2018) showed that only a small number of leading websites dominate the market. One platform constitutes the clear market leader with $93 \%$ of the cis-female sex workers in their sample using it for advertising, and another single platform compromising most of the male sex trade. These authors identify three categories of sex work related sites which fit our definition of ASWs: escort directories, classified websites with an adult section, and multi-service adult entertainment platforms. They also identify different business models of ASWs. While some platforms work with monthly subscriptions that sex workers pay for their advert to be visible, others are free to sign up but charge for premium features such as better placement of advertisements, or for adding information such as direct contact details to their profiles. Websites where sex workers can also sell content or offer webcam and phone sex services generally take a commission from sex workers on the income obtained from this. None of the platforms charge clients of sex workers for signing up, browsing through the adverts, contacting sex workers, or leaving reviews. Some ASWs have implemented extra barriers for migrant sex workers to get verified on their platform, which is frequently driven by assumptions of coercion, exploitation, and trafficking of migrant sex workers specifically. As one operator of a leading ASW told Sanders et al. (2018), they felt a responsibility for ensuring the absence of illegal activities, especially concerning immigration. Some ASWs have obtained a reputation for being racist, xenophobic, exclusionary, and having rules and procedures which are vastly different or more likely to be enforced based on migration status of workers-making the platform a form of a border control itself and part of the 'hostile environment' designed to deter migration (Mac and Smith 2018). One notable ASW, for example, requires migrant workers to buy a recent newspaper and take a picture of themselves, with their face exposed, in front of a street sign in the UK in addition to providing formal ID with their real name on it (Cunningham et al. 2018).

Due to the public nature of the information on ASWs, it comes as no surprise that researchers of the sex industry are increasingly relying on the information provided on online platforms. While there is a large amount of content analyses of the online advertisements of sex workers, including studies on the visibility of LGBTQ sex workers online (Kingston and Smith 2020), the impact of age on the rates for sexual services (Dunn 2018), and the hip-to-waist-ratios of female escorts (Saad 2008), there is surprisingly little interest in the business model and functionalities of the advertising platforms that are used for sampling and recruitment of participants for these investigations. Pajnik et al. (2016), in their analysis of three ASWs in Slovenia, Greece, and France, found that although the emergence of online advertising spaces provides sex workers with more agency, it also tends to 'increase their dependency on powerful entrepreneurs' (p. 348).

\section{ASWs as Intermediaries}

ASWs, as 'powerful entrepreneurs', hold a unique position in the sex trade: they do not fall into the category of employers, but nevertheless have a huge effect on workers. This includes rules limiting certain wording in advertisement, requiring payment for displaying phone numbers or for receiving notifications, requiring use of the website messaging system to engage with potential clients, demanding unique content and media to be uploaded, strict rules on profile verification that are especially demanded of migrant workers, and controlling access to safety features (Barbagallo and Hardy forthcoming). In this way, the control that ASWs hold resembles employer powers. Leighton and Wynn (2011) 
point out that neither 'employee' nor 'self-employed' have been fully defined in UK legislation. Davidov (2004) claims that an employee is characterised by democratic deficits (or control) in relation to their employer, and by economic and social/psychological dependence on the employer. Similarly, Prassl (2016) functional concept of the employer includes as functions: the employer's ability to terminate the employment relationship, employer's ability to profit from labour, employer providing work and pay, employer managing the factors of production (control), and employer managing the enterprise (marketing, venue hire, making loss/profit). In the case of intermediaries, only some of these functions are present. ASWs are able to unilaterally remove any worker from their platform without recourse for the worker, multi-service adult entertainment platforms profit not only through selling advertising space but also through direct profit extraction from the services workers provide on the platform, and although there is no direct control of wages and services, ASWs have a strong influence on the services and prices of workers (Barbagallo and Hardy forthcoming). Especially in the case of large, platform-like ASWs that dominate a section of the market, it is clear that both economic dependence and democratic deficits are in place, with sex workers unable to influence the ASW but the ASW having a large amount of influence on the way sex workers operate. Some ASWs, therefore, can be theorised as intermediaries in in-person sex work, with the ASW facilitating a relationship of dependence between sex workers and their institution.

Like many other platforms outside of the sex industry, such as Uber or Taskrabbit, some ASWs shift entrepreneurial risks onto sex workers to a high degree, including the financial and health risks posed by COVID-19. Online platforms, for instance, shift the financial risk of a lack of customers, worker illness or disability, or changes in the market onto workers (Prassl 2018). Sex work is a great example of a section of the economy that is strongly affected by the pandemic and lockdown, plus an illustration of an industry in which modern forms of employment such as intermediary-ship and online platform work are common. Since ASWs play such an important role in connecting a large proportion of in-person sex workers with their clients, they have the potential to influence the way both clients and workers respond to the COVID-19 pandemic. They have the ability to advise sex workers, clients, or both on risks and alternatives, can add or limit the services they offer, and they can directly or indirectly financially support the workers who use their platform. Currently, the influence of ASWs on sex workers' working conditions is under-theorised and requires further research. The next section will discuss the ways COVID-19 has impacted the income of sex workers and the difficulty sex workers have in accessing support during the pandemic. Then, we will map the ways ASWs have responded to the COVID-19 pandemic in Britain, and analyse the contested relationship between ASWs and sex workers.

\section{The Impact of COVID-19 on Sex Workers}

Sex workers have been affected disproportionally by the pandemic. A large number stopped offering in-person services during the months in which infection rates were highest. Callander et al. (2020b) show that, globally, the number of active advertising profiles of male sex workers drastically decreased. Of those who kept advertising, many made reference to the virus and implemented various strategies to protect themselves from it, such as requiring clients to bring a negative COVID-19 test, refusing to travel, or shifting their services online all together. A small number of profiles mentioned the pandemic by dismissing its existence or downplaying its effect. Callander et al. (2020a) stress that many sex workers have gone back to work in the period between May and August 2020. They call for more academic research to understand what 'safer sex' during COVID-19 looks like, although they also point out that sex worker-led organisations in various countries have published guidelines for sex workers about protective measures.

During the lockdown period in the UK, some sex workers were able to transfer a part of their work to an online market during the pandemic, by offering phone or cam services or creating and selling content online. Other sex workers, however, do not have the resources to do so or do not wish to risk their anonymity by switching to online sex work and therefore had no choice but to continue 
in-person work (Murphy and Hackett 2020). In doing so, they were forced to put their own health at risk while concurrently balancing a stark decrease in clients, resulting in pressure to agree to unsafe practices that they would otherwise avoid (NUM 2020).

Furthermore, a large number of sex workers was excluded from formal governmental support schemes due to the nature of their work. In the UK, the government announced that they will pay a maximum of $80 \%$ of the wages of employed staff as part of the Coronavirus Job Retention Scheme and introduced an additional scheme to support self-employed people (Nicola et al. 2020). However, many sex workers were unable to access these schemes due to the fact that employment relations in the UK are criminalised and therefore even those who are de facto employed by a managed venue, such as a brothel or massage parlour, are nominally self-employed and it follows that they are not eligible for the Retention Scheme (Pitcher 2015). Even in legalised venues, such as strip clubs, dancers are currently legally labelled self-employed (Cruz et al. 2017). Independent workers, who do not have a manager and earn the majority of their income from self-employed work, should be able to claim financial aid through the self-employment support scheme but many are not officially registered as self-employed because they fear stigmatisation or criminalisation by authorities when disclosing that they offer sexual services (Hodgson 2020). In addition, three years of tax documentation of self-employed work is required to qualify for the scheme (HM Revenue \& Customs 2020) which is another barrier for many because sex work is often a transient or short-term form of work (Sanders et al. 2009), meaning that many sex workers do not have a full three-year record of self-employment. Migrant workers in particular, who have not lived in the UK for three years or more, are evidently unable to produce the required documentation (NUM 2020). For those who were eligible for the self-employment income support scheme, the payment was not disbursed until June or July 2020, meaning that for at least three months even the workers who qualified did not receive support (Barbagallo and Cruz forthcoming). Thus, some were faced with the decision between continuing to work and putting their and others' health at risk or losing any source of income for food, rent, and other basic necessities (Murphy and Hackett 2020) ${ }^{2}$.

As a result, sex workers are both highly likely to have their income strongly affected by COVID-19, and are less likely than most workers to be able to access government financial support. This effect is even stronger for migrant workers, who are less likely to access governmental support schemes, regardless of eligibility or migration status (Ehata and Seeleib-Kaiser 2017). In addition to the hurdles that all sex workers face with regards to accessing government support, sex workers without British citizenship were excluded from various schemes due to lack of worker status, criminalisation, or stigma (Platt et al. 2020). Additionally, migrant sex workers may also be less able to pivot their services to online-only provision for a variety of reasons, including lack of access to a private workspace, to a reliable and high-speed internet connection, difficulty with the language requirements of online work, and lack of experience navigating British bureaucracy (Ehata and Seeleib-Kaiser 2017). Therefore, migrant sex workers may have no choice but to keep advertising and providing in-person services. This means this group is even more likely to need to rely on the services ASWs provide even during the pandemic, and therefore to be more affected by the COVID-19 response or lack thereof from ASWs. Before presenting the core results of this research, we will now turn to the methods that we have chosen to collect and analyse our data.

2 For a large number of sex workers, the only source of financial support available to them was a hardship fund set up by a sex worker-led organisation and maintained by sex worker volunteers. The SWARM hardship fund gave out $£ 251.000$ in one-off $£ 200$ donations, but was not able to support all workers who applied (SWARM 2020). In Scotland, the sex worker-led organisation Umbrella Lane was able to distribute funds of over $£ 10,000$ to sex workers and has set up another crowdfunding campaign to continue this support (Umbrella Lane 2020). 


\section{Methods}

This research took place in three parts. First, 45 of the most prominent ASWs in Britain were contacted through email or, if an email address was not publicly available, through the contact form on their website with questions about their response to the COVID-19 pandemic. Following the methodology of Pajnik et al. (2016), we used the Google search engine to conduct internet searches of relevant terms, such as 'escort', 'erotic massage', 'paid date', 'girlfriend experience' and 'call girl'/ 'call boy', to select our sample. We also included the names of locations into the search. At first, we looked at searches of the above-mentioned terms in combination with 'UK', 'United Kingdom', 'Britain', and 'Great Britain', and added 'England', 'Scotland', and 'Wales' as well as the names of the nine official regions of England and the five biggest cities in the UK. We chose the 45 platforms that were either ranked highest in these searches or appeared most often. Five of the contacted ASWs cover only one city and another two focused exclusively on Scotland; the remaining 38 were either nationwide websites or international ASWs with a large UK section.

The first inquiry emails were sent out six weeks after the British government announced lockdown measures since we found this to be an appropriate time to anticipate ASWs to have decided upon their reaction to it. All ASWs were sent an informed consent form outlining the goal of the research and the pseudonymisation process involved, and five questions. The questions asked whether any services or features had been adjusted, added or removed; whether any advice had been given to users of their service or to clients regarding in-person services; whether any contact with sex worker support or sex worker-led organisations had been made during the pandemic; and whether any other actions were taken in response to COVID-19.

Additionally, the public parts of all 45 ASW websites were searched for any notices, posts, pop-ups, banners, or other communications about COVID-19. This is information on COVID-19 that is available to and aimed at clients who use the website to connect with sex workers. This publicly available information and the survey-responses were then pseudonymised and organised in Table 1 which is reproduced in this article. A large amount of this information is publicly available and some ASWs cannot be described without being recognisable to people involved in the industry without losing important data. After multiple attempts at contact we received responses that covered nine ASWs, generating a response rate of $20 \%$. However, seven of those are run by the same individual, and the responses are identical for those ASWs. The majority of the data displayed in Table 1 therefore consists of the public responses of ASWs to COVID-19.

Table 1. Summary of all contacted adult service websites (ASWs) and their COVID-19 response.

\begin{tabular}{|c|c|c|}
\hline Organisation & Description & Covid-19 Response \\
\hline ASW 1 & $\begin{array}{l}\text { One of the main advertising } \\
\text { websites, workers need a free } \\
\text { profile to advertise but pay for } \\
\text { advertising features and links to } \\
\text { their own website. Offers webcam, } \\
\text { phone, chat, and direct sale of } \\
\text { products and pictures in addition } \\
\text { to advertisement. UK-wide. }\end{array}$ & $\begin{array}{l}\text { Paid advertising is still available. A bonus (in website } \\
\text { credits) will be given to the first } 1000 \text { new cam/chat } \\
\text { workers who earn over } 200 \text { credits doing webcam work. } \\
\text { State they donated to three hardship funds. Additionally, } \\
\text { sex worker-led organisations confirmed ASW } 1 \text { removed } \\
\text { their free security feature during lockdown. Paid } \\
\text { advertising features have stayed intact. }\end{array}$ \\
\hline ASW 2 & $\begin{array}{l}\text { UK-wide, classified advertisement } \\
\text { website with a large adult section. }\end{array}$ & $\begin{array}{l}\text { Matched donations up to } £ 100,000 \text { to a British hardship } \\
\text { fund and donated } £ 10,000 \text { to a local hardship fund, } \\
\text { posted on their website on support available to sex } \\
\text { workers and on moving work online. Banned ads for } \\
\text { in-person meets and made their online-only advertising } \\
\text { free during lockdown. }\end{array}$ \\
\hline
\end{tabular}


Table 1. Cont.

\begin{tabular}{cll}
\hline Organisation & \multicolumn{1}{c}{ Description } & \multicolumn{1}{c}{ Covid-19 Response } \\
\hline ASW 3-9 & $\begin{array}{l}\text { Seven smaller directories run by } \\
\text { the same person, including } \\
\text { directories local to Scotland and } \\
\text { London, and for niches within the } \\
\text { female escort industry. }\end{array}$ & $\begin{array}{l}\text { Donated to a hardship fund, made featured advertising } \\
\text { free during lockdown, connected workers using their } \\
\text { directories with a Scottish sex worker-led organisation at } \\
\text { the organisation's request. Notice on some sites but not } \\
\text { others on COVID-19, urging users to donate to } \\
\text { organisations that support sex workers. }\end{array}$ \\
ASW 10 & $\begin{array}{l}\text { Large, UK-wide gay } \\
\text { male directory. }\end{array}$ & $\begin{array}{l}\text { Blog posts and the website urge clients to have webcam } \\
\text { and phone sex instead, to support the workers. They also } \\
\text { sell a branded face mask in their shop. }\end{array}$ \\
\hline ASW 11-15 & $\begin{array}{l}\text { UK, London, European, and } \\
\text { Scottish directories. }\end{array}$ & $\begin{array}{l}\text { Launched new non-contact features on their website } \\
\text { during the lockdown: phone chat, video, webcam, or } \\
\text { specific non-contact advertising. }\end{array}$ \\
\hline ASW 16-22 & $\begin{array}{l}\text { European directories with a large } \\
\text { UK section. }\end{array}$ & $\begin{array}{l}\text { A pop-up, banner, or notice on the website } \\
\text { mentioning COVID-19. }\end{array}$ \\
\hline ASW 23-45 & All other ASWs in the sample. & $\begin{array}{l}\text { No notifications or information on their website } \\
\text { about COVID-19. }\end{array}$ \\
\hline
\end{tabular}

In the second part of this research, we contacted nine established sex worker-led organisations, meaning groups that support or advocate for sex workers and whose work is driven by sex workers themselves. They were contacted via email four weeks after first reaching out to the ASWs. Of these organisations, five operate in England, two in Scotland, and two in the whole of Britain. They were also sent an informed consent form in addition to four questions and the pseudonymised data on ASWs collected. The sex worker-led organisations were asked to verify or correct the information in as far as they were able to; asked whether they had been contacted by or received donations from any ASWs; whether they knew of any further ASW responses to the pandemic; and to share which response they would have liked to see from ASWs during the COVID-19 pandemic. Of the nine sex worker-led organisations, seven responded: four of them England-based, two from Scotland, and one Britain-wide group. Data from participants and publicly available sources were qualitatively analysed and content analysis was used for qualitative analysis of the data.

Out of nine sex worker-led organisations contacted, seven decided to participate in this research. The rate of response is therefore much higher than amongst ASWs. Although many sex worker-led organisations were especially busy supporting workers during lockdown, and although the mistrust of sex workers and their organisations towards researchers is well-documented (Jeffreys and Regional Think Tank on Sex Worker Research 2010), sex worker-led organisations seemed more willing to engage on this topic than ASWs. Of the participating organisations, two are based in Scotland, two in England, one in the North of England, and two operate nationwide. The goal in contacting sex worker-led organisations in addition to ASWs was threefold. Firstly, we felt that it would be unethical to request time and effort from a large number of workers during such a difficult and stressful time by surveying individual sex workers, and chose instead to ask a smaller number of representative organisations to share their collective insights. Secondly, they are best placed to triangulate the information given by ASWs, since they have direct information about ASWs contacting them or donating to their organisations. This allowed us to not only verify the information given to us by ASWs, but also provided additional information that covered non-respondent ASWs. Thirdly, this provided us with the opportunity to ask activists highly engaged with sex worker rights and working conditions about their views on the ways ASWs would be able to productively respond to COVID-19.

\section{Results}

Many platforms appeared to have a general awareness of the difficulties that sex workers are facing due to COVID-19. For instance, one ASW commented 'We recognise that the pandemic and resulting lockdown will have a particularly negative impact on sex workers and that many will be 
facing financial hardship, especially if they are not able to offer online services. We want to do what we can to help them at this difficult time' (Survey response, ASW 2, national classified advertising website). Other ASWs, however, stressed that they were not an employer in the traditional sense and thus felt very little responsibility towards sex workers advertising on their website by stating that they were 'strictly an advertising page' (Survey response, ASW 3-9, owner of seven smaller/niche websites, national and Scotland only) or 'not an escort agency' (Survey response, ASW 26, international directory with a large UK section). These responses reflect the ambiguous relationship between sex workers and ASWs. In some ASWs' view, the fact that they do not employ sex workers and are not an escort agency means they are not required to, nor should they be expected to, support the financial and physical wellbeing of the workers using their platforms. This frequently resulted in no or few changes to the functionality of their business. Although the sites differed significantly in size, traffic, and popularity, this had no detectable effect on their response to COVID-19. Other ASWs, however, recognised their intermediary or intermediary-like role and viewed the health and income of sex workers as within their sphere of influence. As a consequence, they implemented measures to mitigate the potential harm of COVID-19 on the sex workers who use their platform. These ASWs, however, were more likely to view this as 'help' than as a responsibility inherent to their role as ASW.

\subsection{ASW Responses}

Measures introduced by some ASWs in response to COVID-19 include public advice about the virus, new online features, scraping of the advertising charges, the provision of additional safety features, and engagement with as well as donations to sex worker-led organisations. The various actions of the analysed ASWs are summarised and categorised in Table 1.

Of the 45 analysed ASWs, nearly half $(48.89 \%, \mathrm{n}=22)$ did not post any public notice to inform clients of sex workers about alternatives, continued to take payments for adverts, and displayed no publicly visible response to or acknowledgement of COVID-19 on their website. Since most of these ASWs did not respond to our contact, it is impossible to say whether they have used internal messaging to contact the sex workers who use their website, but a lack of public messaging does show that most clients will not have been informed of the risks of and alternatives to meeting sex workers in-person during lockdown. One respondent, while having no publicly visible response to COVID-19, did use their internal messaging system to suggest workers use phone or cam services, saying "we have advised sex workers to simply choose other options that will help them stay healthy while still making money" (Survey response, ASW 26, international directory with large UK section). The language used to describe this move to online services has a focus on pleasure, ease, and income, avoiding language about health or responsibility: "Sex on the phone or on the camera is still extremely enjoyable and it can offer amazing pleasure. Clients will definitely be very happy to pay for these services as well" (ibid.).

\subsubsection{Public Advice}

For some ASW's, their sole response to COVID-19 was to create a publicly visible notice or banner on their website about the pandemic $(15.56 \%, n=7)$. Most were small banners that focused on encouraging sex workers and clients to find pleasure in online services or to hold off on bookings for a while. Some ASWs took a more direct stance. ASW 16 (international directory with a large UK section) used a pop-up on their website that prevents the user from entering without agreeing with their firmly worded statement:

"STOP SPREADING THE CORONAVIRUS TOGETHER. To protect public health and combating the further spread of the Corona virus is a top priority in addition to stop physical contact in this time of the Corona crisis. Please accept the governments actual regulations in this regard and declare that you abide by them by clicking the "Enter" button below."

However, once on the websites, all services are still available and no further references to COVID-19 are present. Another exception is ASW 10 (national advertising site), the only ASW in the sample 
that is aimed solely at the gay male market, and the only website that aims their public messaging at clients rather than sex working-placing the responsibility for healthy behaviour solely on clients and urging them use webcam and phone services to support sex workers. Their website also publicly states "We urge people not to meet during the C-19 lockdown and protect our NHS staff-we do however urge you to contact escorts by phone and make bookings for the future when both parties can meet safely-Remember also that webcam bookings are a great way to have company during these difficult times". This wording stands in strong contrast with the less health oriented and more marketing focused language used on websites that focus on straight male clients and female sex workers, which acknowledges the seriousness of the virus to a much lesser extent and makes no mention of public health responsibilities of clients:

"\#stayhome If you care about yourself, stay home. We'll be meeting each other again with no fear -) Look for VideoChat ad and \#everythingwillbefine" (ASW 19, international directory with a large UK section).

\subsubsection{New Online Features}

Another popular response to the pandemic was to either introduce new webcamming or phone services $(11.11 \%, \mathrm{n}=5)$ or signpost to already existing external camming websites $(31.11 \%, \mathrm{n}=14)$. An additional $11.11 \%(n=5)$ had established online services on their site previously and encouraged both sex workers and their clients to make use of that section rather than meet up in-person. ASW 1 (large national advertising site), who has a longstanding webcam section forming a minor part of the market, publicly announced that the first 1000 sex workers who started offering webcam services during lockdown to earn over a certain amount, would be paid a bonus in website credits. These credits can be used to buy advertising features for in-person work, or can be paid out after a $30 \%$ cut is taken by the ASW.

\subsubsection{Advertising Charges}

A minority of ASWs, $20 \%(n=9)$, made previously paid advertising free for the duration of lockdown to allow sex workers to arrange future meetings and keep their search engine optimisation (SEO) intact. In the words of one respondent "All charges for featured advertising have been removed until business resumes. No one has the money to spend in any case. For SEO website ranking, advertising it is vital to keep this in place" (Survey response, ASW 3-9). ASW 2 chose to ban in-person adverts entirely but instead offered free advertising for online services: "In line with Government guidance on social distancing, we took a decision not to allow adverts for face-to-face offerings on the site. We asked users to remove references to meeting in person and we removed pricing options for in-person services. We have tried to ensure adverts on our site do not contain references to meeting in person, by manually reviewing the descriptions" (Survey response, ASW 2). The majority of the platforms we contacted, however, continued charging for adverts on their site.

\subsubsection{Ensuring Safety}

Ensuring the safety of sex workers during this crisis was engaged with in different ways. While some ASWs increased their individual safety support and/or signposted to support services and hardship funds for sex workers on their website and social media, others showed less concern for the safety of those who continued in-person sex work throughout the pandemic. ASW 2 shared resources of both the government and sex worker-led organisations with users: "We have ensured that resources and information about the coronavirus and social distancing was available to users through the Safety Centre, including Government guidance, signposting to help available through sex worker support groups and financial hardship funds" (Survey response, ASW 2). ASW 1 announced on their public Covid-19 information page that they had removed their safety feature for in-person meets in 
order to 'prevent the determined and as a failsafe' (national advertising website with webcamming and phone section).

\subsubsection{Engagement with Sex Worker-Led Organisations}

The owners of a small number of the contacted platforms $(6.67 \%, \mathrm{n}=3)$ donated to sex worker-led charities and hardship funds, or matched donations made by private individuals. These donations ranged from $£ 300$ to a sex worker-led organisation local to a regional ASW, to $£ 100,000$ in donation matching to a national sex worker-led hardship fund. Additionally, some ASWs reached out to sex worker support projects, such as National Ugly Mugs, in order to determine what support the wider sex working community needed and to share information on hardship funds with their users.

The wide variety in responses to COVID-19 shows that the ambiguous role of ASWs as intermediaries causes large differences between ASWs that recognise the relationship of dependence between themselves and sex workers, and those that do not. Where a large portion of ASWs do not seem to view themselves as having any responsibility for the health or income of sex workers-preferring to see them only as service users-others recognise that the sex workers who pay for their services are uniquely vulnerable during COVID-19 and take a wide variety of steps in support of workers. The following section will contrast these findings with the responses of ASWs to COVID-19 that sex worker-led organisations would have liked to see.

\subsection{Sex Worker-Led Organisations}

The participating sex worker-led organisations confirmed that the information given by ASWs (summarised in Table 1) is correct to their knowledge. They confirmed that funds have been received when ASWs stated this, and that any changes in features or communication to ASW users have indeed taken place. Sex worker-led organisations also confirmed that workers have encountered problems in accessing local and national government financial support. This is best illustrated by an anecdote of a member of one sex worker-led organisation participating in this research. She applied for financial support from her Northern English council to move her business online. While this was advertised publicly to all local sole traders, the council denied her access as this may have a "reputational risk for the council which outweighed the economic benefits of supporting her application". The council later agreed there were no legitimate grounds for refusal and reversed their decision after pressure from several sex worker-led organisations.

When asked about the response they would have liked to see from ASWs during the pandemic, the participating sex worker-led organisations all clearly expected some form of action from ASWs in excess of the response that had been present. They identified seven distinct actions that ASWs could have taken during the lockdown: free or reduced fee advertisement, increasing online opportunities, increased support and security for online features, donations to sex worker-led organisations, promoting sex worker-led organisations to ASW users, direct engagement with sex worker-led organisations, and urging clients-rather than workers-to avoid in-person meetings.

\subsubsection{Free Advertisement}

Most sex worker-led organisations explicitly stated that after the end of lockdown, it is essential for workers to have access to free or reduced fee advertisements "given a large period of time will have passed of not being able to work" (Survey response, Scottish organisation). A variety of different ways of offering workers free or reduced fee advertisement were suggested, from temporarily dropping all advertising fees, to providing a limited amount of credit to all ASW users at the end of lockdown, providing free services for workers moving to online work, or a limited amount of days of free advertising. All these interventions would have the benefit to ASWs of making sure their users can continue to use their service in the long run. 


\subsubsection{Online Opportunities}

While many ASWs responded to COVID-19 by extending their platforms to include phone or cam sex options, only one sex worker-led organisation mentioned they would like to see ASWs take this action. However, they emphasised the importance that these online alternatives should not be used to exclude or fine workers for whom online work is not a viable option: "boost ability to interact online without penalising those who choose to do in person work still" (Survey response, national sex worker-led organisation). This is in stark contrast with action taken by ASW 2, forbidding all mention of in-person meets during lockdown in sex workers' advertising.

\subsubsection{Support and Security}

Several sex worker-led organisations emphasised the importance of workers having access to support and security for online features during COVID-19, especially the protection of sex workers' privacy and security measures that protect them from potentially violent clients. Likely in response to ASW 1 removing a key security feature during COVID-19, one sex worker-led organisation operating in the North of England stated "If ASW's could keep in place all security measures that would be great.". There was outrage and confusion among sex worker-led organisations about the removal of this safety feature, since working during COVID-19 has become less safe and thus safety features were seen as more important than ever. One of the participating organisations stressed that they would like ASWs to "improve their lax security generally, and their persecutory attitude that some Adult Service Websites have towards sex workers". This speaks to a level of mistrust between sex workers and ASWs, which sex workers seem to feel is mutual in some cases.

\subsubsection{Donations to Hardship and Emergency Funds}

Donations, either directly to hardship funds set up by sex worker-led organisations in response to COVID-19 or to sex worker-led organisations in general, are also regularly mentioned. One sex worker-led organisation stated: "Larger ASWs should definitely donate more to hardship funds etc, but also consider doing regular donations to sex worker led organisations on a permanent basis". This acknowledges that not all ASWs derive profits from sex workers to the same extent, and that sex worker-led organisations feel that those ASWs who receive more payments from sex workers also should hold more responsibility towards sex workers in times of crisis.

\subsubsection{Promotion of and Engagement with Sex Worker-Led Organisations}

The importance of ASWs promoting the existence of sex worker-led organisations and support options to their users, especially during the pandemic when several sex worker-led organisations have set up hardship funds, was also emphasised by a Scottish organisation: "We would also like to see them better advertise sex worker led support services and open a direct link to communicate with our projects to do things like share surveys, share events etc to advertising workers". The organisations also emphasised they would like ASWs to directly engage with and share information with sex worker-led organisations, and to do this rather than engage with organisations that want to criminalise sex workers or their clients. One Scottish sex worker-led organisations discussed a recent best practice example where ASW 3 collaborated with a local organisation: "This stance was recently taken by [ASW 3], a small escort platform in Scotland who reached out to [us] to say they were approached by an abolitionist organisation to share their resources to workers through their network. [ASW 3] reached out to [us] to enquire if we knew of the organisation and their stance on prostitution. We informed them this organisation support the criminalisation of clients and actively campaign for this legal framework. [ASW 3] then went back to the organisation to make clear they only work with sex worker led organisations that support labour rights and decriminalisation." Another organisation based in Scotland added that in the same situation they "advised the owner of ASW3 to inform any users in need of the [local] hardship fund". ASW 3, which has since shared the information of a local sex 
worker-led organisation hardship fund with its users, has shown that direct communication and cooperation between ASWs and sex worker-led organisations is not only possible but very beneficial. However, only ASW 3 and ASW 2-via a mediating organisation-have implemented such cooperation during COVID-19.

\subsubsection{Client Responsibility}

Finally, one sex worker-led organisation mentioned the desire for ASWs to put the responsibility to avoid in-person meetings on clients rather than sex workers: "a message especially for clients advising them not to ask for meets during this time to safeguard workers. Maybe a pop up when they try to send a message". None of the responding ASWs have implemented a policy that focuses on clients rather than sex workers, and only one of the ASWs (ASW 10) has a notice on their website which puts responsibility not to meet in-person on clients rather than workers, urging them to meet online in order to protect sex workers.

\subsubsection{Migrant Workers}

In addition to the questions posed to them, sex worker-led organisations also were asked to provide any additional information they felt is relevant to ASWs response to COVID-19. Both organisations that provided this information focused on the unbalanced power relations between ASWs and migrant sex workers. An England-based organisation stressed that with sex workers being in financial difficulty during lockdown "the structural injustices of the online advertising sites that existed before COVID-19 are even more of a problem now as things have got harder and sex workers feel more under attack. For example, the requirement for people to provide their passports and the lax security that some websites have." A Scottish organisation added that specifically ASW 1 "has a history of being discriminatory towards migrant workers, frequently removes users accounts for punitive and unfair reasons, cutting off their main source of income, and has been unhelpful, patronising and dismissive in person during liaisons with our organisation and others." The unequal power relationship between sex workers and ASWs is seen by sex worker-led organisations to affect migrant workers especially.

\section{Discussion}

The high number of adult service websites who did not respond to COVID-19, or who responded only minimally, stands in contrast with the high level of control some ASWs have over sex workers, as identified by Barbagallo and Hardy (forthcoming). It has become clear both from the pandemic response and from their responses to our research questions that most ASWs do not feel responsible for the economic and health risks to sex workers who use their services in the same ways as an employer would. This tendency is similar to what has been identified on other platforms in modern capitalism, such those facilitating food delivery or private car hires (Barbagallo and Hardy forthcoming). Some ASWs explicitly reject this responsibility, emphasising that they are not employers of sex workers, which reflects on the ambiguity of the relationship of dependence (Davidov 2004). They thus take no further action, while others implement a range of changes in order to support and protect the income and health of sex workers during the pandemic. This difference cannot be explained by the size of the ASW, or the level of control the ASWs exercise over sex workers. Additionally, sex worker-led organisations make clear that in their view sex workers are not simply ASW service users, and describe a range of responsibilities or commitments that they want or expect ASWs to take towards supporting the sex workers they directly profit off. This imbalance in perceptions of responsibility and dependence is mirrored in the relations between workers and non sex work platforms, where the rights of the workers on the platform are negotiated in court, in unions, and through direct action (Forde et al. 2017).

At least one ASW did not change their policies, did not recommend clients to switch to online services nor put a notice up on their website, yet contacted sex workers through the private direct message function of their website recommending they offer online instead of face-to-face services. 
In doing so, they put the burden of preventing the spread of COVID-19 and working within government guidelines on the workers, rather than taking on this responsibility nor putting it on clients. Other ASWs published notices or banners either urging sex workers to do online work, or highlighting the enjoyment that can be derived from online services. A possible explanation for this can be that warnings aimed at sex workers rather than clients do not risk scaring off any clients or losing any advertisement money. It is notable that the only ASW that did encourage clients rather than sex workers to change their behaviour and protect workers is a site aimed at gay male clients. This indicates that since the gay male community has decades of experience in normalising conversations about health and risk in sexual environments (Woods et al. 2001), an ASW with a gay male audience may feel it is less likely to risk loss of customers due to clear messaging on COVID-19. However, the possible fear of losing clients of ASWs that focus on the straight market once again shows that sex workers are not simply site users of ASWs in the same way that their clients are-no ASW expressed a fear of losing sex worker users or advertisement income due to COVID-19 messaging being too direct when aimed at sex workers. This makes the argument of some ASWs that they do not have employer-like responsibilities a less convincing one, since they are happy to exercise control over the sex workers who advertise on their platform, but not over their clients.

Although some ASWs paused payments for advertisement, most did not. By continuing to make sex workers pay for their ads, or by launching new camming and phone services and taking commission from sex workers' earnings on those services, ASWs shift the financial risks that COVID-19 introduced from the platform to sex workers. This is similar to the process by which, through house fees and fines, the main source of income of lap dancing clubs in the UK has become the workers rather than the clients (Hardy and Sanders 2014) and entrepreneurial risks have been moved from club owners to independently contracted workers. This entrepreneurial risk placed on workers stands in contrast to the control and power exerted by ASWs, for instance in their verification procedures for migrant workers or by policing the language used in ads during the pandemic. This combination of control and a shifting of financial risk may be highly profitable for ASWs (Barbagallo and Hardy forthcoming), but exacerbates the financial and health vulnerabilities of sex workers during the pandemic, especially those of migrant workers without recourse to governmental support.

Future research of the role of ASWs in the working lives of sex workers should include the interplay between the criminalisation of third parties in Britain and sex workers' dependence on ASWs. This includes the question whether the criminalisation of organised workspaces, including brothels and agencies, forces some sex workers to instead work independently and use ASWs to attract clients and in doing so increases the level of control that ASWs have over workers. In contrast, the power of ASWs that have intense and border-like verification procedures may push migrant workers to work with third parties even if they would prefer to work independently (Mai 2013). A further avenue for exploration is the COVID-19 response of dating, sugar dating, and video apps and websites which are often used by sex workers to either connect with potential clients or sell content. The adult entertainment website OnlyFans, for example, reported a massive increase in the number of creators in the UK during the pandemic (Jones 2020), indicating the rise in dependency of sex workers on the online market. The contrast in financial models between these apps and ASWs may shed more light on the relationship of dependence between ASWs and sex workers.

Author Contributions: Conceptualization, L.B. and T.H.; Methodology, L.B. and T.H.; Formal Analysis, L.B. and T.H.; Resources, L.B.; Data Curation, L.B. and T.H.; Writing-Original Draft Preparation, L.B. and T.H.; Writing-Review \& Editing, L.B. and T.H.; Project Administration, L.B. and T.H. All authors have read and agreed to the published version of the manuscript.

Funding: This research received no external funding.

Acknowledgments: We would like to thank all organisations who took the time to respond to our call for participants, especially the members of sex worker-led organisations who are currently working hard to minimise the impact of the pandemic on their most-affected members. Many thanks to the Centre for Employment Relations, Innovation and Change (CERIC) at the Leeds University Business School for support with APC costs. We also 
want to thank Kate Hardy for valuable feedback and input while this article was in development, and Isabelle Huning for breaking up many of our run-on sentences.

Conflicts of Interest: The authors declare no conflict of interest.

Ethics Statement: All participating organisations gave their informed consent for inclusion before participation in the study. Information about non-responding organisations has been gathered from publicly available sources. The study protocol was approved by the AREA Ethics Committee of the University of Leeds.

\section{References}

Barbagallo, Camille, and Katie Cruz. Forthcoming. Dancers Win at Work: Unionisation and Nowak v Chandler Bars Group Ltd. Studies of Political Economy.

Barbagallo, Camille, and Kate Hardy. Forthcoming. Hustling the Platform: Sex Work, Digital Technology, and Organising for Power. South Atlantic Quarterly.

Brown, Kate, Scarlett Redman, and Sharon Grace. 2019. Policing Vulnerability: Learning from Sex Work Liaison Officer Role in West Yorkshire Police N8 Policing Research Partnership. Available online: https://n8prp.org. uk/policing-vulnerability-learning-from-sex-work-liaison-officer-role-in-west-yorkshire-police/ (accessed on 29 August 2020).

Callander, Denton, Étienne Meunier, Ryan DeVeau, Christian Grov, Basil Donovan, Victor Minichiello, Alicia Singham Goodwin, and Dustin T. Duncan. 2020a. Sex workers are returning to work and require enhanced support in the face of COVID-19: Results from a longitudinal analysis of online sex work activity and a content analysis of safer sex work guidelines. Sexual Health 17: 384-86.

Callander, Denton, Étienne Meunier, Ryan DeVeau, Christian Grov, Basil Donovan, Victor Minichiello, Jules Kim, and Dustin Duncan. 2020b. Investigating the effects of COVID-19 on global male sex work populations: A longitudinal study of digital data. Sexually Transmitted Infections. [CrossRef]

Cruz, Katie, Kate Hardy, and Teela Sanders. 2017. False Self-Employment, Autonomy and Regulating for Decent Work: Improving Working Conditions in the UK Stripping Industry. British Journal of Industrial Relations 55: 274-94. [CrossRef]

Cunningham, Scott, and Todd D. Kendall. 2010. Prostitution 2.0: The Changing Face of Sex Work. Journal of Urban Economics 69: 273-87. [CrossRef]

Cunningham, Stewart, Teela Sanders, Jane Scoular, Rosie Campbell, Jane Pitcher, Kathleen Hill, Matt Valentine-Chase, Camille Melissa, Yigit Aydin, and Rebecca Hamer. 2018. Behind the Screen: Commercial Sex, Digital Spaces and Working Online. Technology in Society 53: 47-54. [CrossRef]

Davidov, Guy. 2004. Joint Employer Status in Triangular Employment Relationships. British Journal of Industrial Relations 42: 727-46.

Dunn, Michael J. 2018. Younger escorts advertise higher charges online than older escorts for sexual services cross-culturally. Evolutionary Psychological Science 4: 331-39. [CrossRef]

Ehata, Rebecca, and Martin Seeleib-Kaiser. 2017. Benefit Tourism and EU Migrant Citizens: Real-World Experiences. Social Policy Review 29: 181-97.

Forde, Chris, Mark Stuart, Simon Joyce, Liz Oliver, Danat Valizade, Gabriella Alberti, Kate Hardy, Vera Trappmann, Charles Umney, and Calum Carson. 2017. The Social Protection of Workers in the Platform Economy. Brussels: Policy Department-Economic and Social Policy, Employment and Social Affairs (European Parliament).

Hardy, Kate, and Teela Sanders. 2014. Flexible Workers: Labour, Regulation and the Political Economy of the Stripping Industry. London: Routledge.

HM Revenue \& Customs. 2020. How HMRC Works out Trading Profits and Non-Trading Income for the Self-Employment Income Support Scheme. Gov.uk. GOV.UK. April 14 . Available online: https://www.gov.uk/guidance/how-hmrc-works-out-total-income-and-trading-profits-for-the-selfemployment-income-support-scheme (accessed on 18 August 2020).

Hodgson, Nichi. 2020. Sex Workers and Covid-19: What the Virus Means for Britain's Least Protected Self-Employed. The Critic. Available online: https://thecritic.co.uk/sex-workers-and-covid-19/ (accessed on 29 August 2020).

Jeffreys, Elena, and Regional Think Tank on Sex Worker Research. 2010. Sex Worker-Driven Research: Best Practice Ethics. Dialogue 8: 1-20.

Jones, Angela. 2015. Sex Work in a Digital Era. Sociology Compass 9: 558-70. [CrossRef] 
Jones, Lora. 2020. Only Fans: ‘I Started Selling Sexy Photos Online after Losing My Job. BBC News, July 15. Available online: https://www.bbc.co.uk/news/business-53338019 (accessed on 19 August 2020).

Kingston, Sarah, and Nicola Smith. 2020. Sex Counts: An Examination of Sexual Service Advertisements in a UK Online Directory. The British Journal of Sociology 71: 328-48. [CrossRef] [PubMed]

Leighton, Patricia, and Michael Wynn. 2011. Classifying Employment Relationships-More Sliding Doors or a Better Regulatory Framework? Indiana Law Journal 40: 5-44. [CrossRef]

Mac, Juno, and Molly Smith. 2018. Revolting Prostitutes. London: Verso Books.

Mai, Nick. 2013. Embodied cosmopolitanisms: The subjective mobility of migrants working in the global sex industry. Gender, Place E Culture 20: 107-24.

Murphy, Paige, and Tayler Hackett. 2020. Sex Work, Covid-19 and the UK Lockdown. London: Verso Books, Available online: https://www.versobooks.com/blogs/4638-sex-work-covid-19-and-the-uk-lockdown (accessed on 27 July 2020).

NHSGGC Communications. 2020. Covid-19 Advice for People Who Sell Sex. NHS Greater Glasgow. Available online: https://www.nhsggc.org.uk/your-health/health-issues/covid-19-coronavirus/for-patients-the-public/ local-support-services/sexual-health-services-sandyford/advice-for-people-who-sell-sex/\# (accessed on 18 August 2020).

Nicola, Maria, Zaid Alsafi, Catrin Sohrabi, Ahmed Kerwan, Ahmed Al-Jabir, Christos Iosifidis, Maliha Agha, and Riaz Agha. 2020. The socio-economic implications of the coronavirus pandemic (COVID-19): A review. International Journal of Surgery 78: 185. [CrossRef]

NPCC. 2019. National Policing Sex Work and Prostitution Guidance. Version 2. Available online: http://library.college.police.uk/docs/appref/Sex-Work-and-Prostitution-Guidance-Jan-2019.pdf (accessed on 23 August 2020).

NUM. 2020. Evidence submitted by National Ugly Mugs (CVG0014). Women and Equality Committee Website. Available online: https:/committees.parliament.uk/writtenevidence/8610/pdf/ (accessed on 25 August 2020).

Pajnik, Mojca, Nelli Kambouri, Matthieu Renault, and Iztok Šori. 2016. Digitalising Sex Commerce and Sex Work: A Comparative Analysis of French, Greek and Slovenian Websites. Gender, Place and Culture: A Journal of Feminist Geography 23: 345-64. [CrossRef]

Pitcher, Jane. 2015. Sex work and modes of self-employment in the informal economy: Diverse business practices and constraints to effective working. Social Policy and Society 14: 113-23. [CrossRef]

Platt, Lucy, Jocelyn Elmes, Luca Stevenson, Victoria Holt, Stephen Rolles, and Rachel Stuart. 2020. Sex Workers Must Not Be Forgotten in the COVID-19 Response. Lancet 396: 9-11.

Prassl, Jeremias. 2016. The Concept of the Employer. Oxford: Oxford University Press.

Prassl, Jeremias. 2018. Humans as a Service: Promise and Perils of Work in the Gig Economy. Oxford: Oxford University Press.

Saad, Gad. 2008. Advertised waist-to-hip ratios of online female escorts: An evolutionary perspective. International Journal of e-Collaboration (IJeC) 4: 40-50.

Sanders, Teela, Jane Scoular, Rosie Campbell, Jane Pitcher, and Stewart Cunningham. 2018. Internet Sex Work: Beyond the Gaze. Cham: Springer.

Sanders, Teela, Laura Connelly, and Laura Jarvis King. 2016. On Our Own Terms: The Working Conditions of Internet-Based Sex Workers in the UK. Sociological Research Online 21: 133-46. [CrossRef]

Sanders, Teela, Maggie O'Neill, and Jane Pitcher. 2009. Prostitution: Sex Work, Policy and Politics. London: Sage Publications Limited.

SWARM. 2020. How We Ran a Mutual Aid Fund, SWARM Collective. Available online: https://www. swarmcollective.org/briefing-documents-publications (accessed on 18 August 2020).

Umbrella Lane. 2020. Emergency Fund \& Online Resources Information. Available online: https://www. umbrellalane.org/emergency-fund-online-resources (accessed on 18 August 2020).

Woods, William J., Diane Binson, Tracy J. Mayne, L. Robert Gore, and Greg M. Rebchook. 2001. Facilities and HIV Prevention in Bathhouse and Sex Club Environments. Journal of Sex Research 38: 68-74. [CrossRef]

(C) 2020 by the authors. Licensee MDPI, Basel, Switzerland. This article is an open access article distributed under the terms and conditions of the Creative Commons Attribution (CC BY) license (http://creativecommons.org/licenses/by/4.0/). 